\title{
Analysis of Presenteeism among Nurses
}

\author{
Nur Syahirah Mohd Asri, Norshahrizan Nordin
}

\begin{abstract}
Nurses' presenteeism surveys are essential in order for a healthcare organization to obtain a comprehensive understanding pertaining to the nurses' problem and also their needs regarding the relationship between elements of nature of work, social support, physical work environment and social status with presenteeism. A study is a vital tool to investigate the relationship between elements of nature of work, social support, physical work environment and social status which leads to the frequency of presenteeism among nurses in the hospital. This study was a correlational research about the relationship between elements of nature of work, social support, physical work environment and social status with presenteeism among nurses in government hospital at Perlis and Kedah state. A convenience sampling technique was used and 120 respondents were statistically calculated. Only respondents who nurses served treatment and care in government hospital at Perlis and Kedah state were included in this study. The components of presenteeism study were the socio-demographic characteristics, the elements of nature of work, social support, physical work environment and social status as well as nurses' presenteeism. This study aimed to find the significant relationship between independent and dependent variables. It was revealed that the elements of nature of work, social support, physical work environment and social status were lead to presenteeism among nurses in government hospital at Perlis and Kedah state. Besides, there are some aspects that should be considered by government hospital at Perlis and Kedah state in order to knowledgeable the frequency of presenteeism among their nurses. Since nurses' presenteeism seems to be the most important element in Perlis and Kedah state, it is beneficial for the hospital management to encourage their nurse to pretend good and excellent without poor health condition and decreases the frequency of presenteeism with the elements of nature of work, social support, physical work environment and social status.
\end{abstract}

Index Terms: Presenteeism; Psychosocial Factors; Nature of Work; Social Status; Physical Work Environment; Social Status

\section{INTRODUCTION}

\section{A. Background of Study}

Generally, nurses play important role in health care setting either in government or the private sector. The nurse was needed the most at all the time to assist the physician and other health care provider in giving treatment to the patient. Therefore, it was important for the organization to ensure their nurses were always attending work with a good health condition to performing their daily task to patients. In addition, nurses are one of the healthcare professionals who are at the forefront of patient care and responsible in providing the care that they believed patients need. According to International Council of Nurses (2018), definition of nursing is encompasses autonomous and collaborative care of individuals of all ages, families, groups, and communities, sick or well and in all settings. Nursing includes the promotion of health, prevention of illness, the care of ill, disabled and also dying people. Furthermore, the key nursing roles are advocacy, promotion of a safe environment, research, participation in shaping health policy between patients and health systems management, and also education. The relationship between nature of work on presenteeism revealed that the nurses whose attend work with the type of work that he or she does. This can refer to the basic daily tasks carried out as part of a nurses' job and can refer to other non-routine tasks that may be required. Added together, the characteristics of these tasks comprise the nature of nurses' work. The nature of this work may be summed up in the nurses' title (Lewis J., 2013). According to Noraini Othman \& Aizzat Mohd Nasurdin (2011), the nature of workplace adversity for nurses need them to build the inner strengths in the form of psychological capital, in order to be able to cope with and protect themselves from the effects of workplace adversity. Without these inner strengths, nurses may experience negative feelings such as burnout and depression. Throughout time, nurses' jobs will always surround with elements of stressful, difficult situations, episodes of hardship, unstable work time, excessive workload, paper work and so on may performing well even though in poor health condition. The job demand may lead to be positive or negative outcomes depending on the demand itself as well as on the individual's ability to cope with it. Positive outcomes may be a motivation, stimulation or job-satisfaction while negative outcomes can be depression, anxiety or burnout. Current evidence reveals job satisfaction as a predictor of the length of stay in a job, motivation and job productivity. Meanwhile, the level of job satisfaction among nursing staff is dropping all over the world though (Caricati L.,Sala R. L., Marletta, G. et al, 2014). Relationship between social supports on presenteeism revealed that support from the supervisory support affect the nurses' staff to monitor better on their patient when supervisor and other nurses became team player and help each other when have problems and it simplifies the nurses. According to Luo $\mathrm{Lu}$ et al, positive personal and work-related factors such as hardy personality and work support which might perform protective roles in the presenteeism processes has been overlooked $(\mathrm{Lu}$, L., Cooper, C. L., \& Lin, H. Y., 2013). Thus, their second aim of the study is to examine the role of supervisory support, an important work resource, as a stress buffer for people working in different cultural contexts. 
Analysis of Presenteeism among Nurses

Other than that, physical environment on presenteeism revealed that those nurses who attend work in healthy condition tends to delivered excellent services if the physical

According to Business Dictionary (2018), physical work environment is defined as when pertaining to a place of employment, the work environment involves the physical geographical location as well as the immediate surroundings of the workplace, such as an office building. Typically, other factors relating to the place of employment such as the quality of the air, noise level and additional perks. Other than that, other benefits of employment such as free child care or unlimited coffee or adequate parking.

Meanwhile, the physical work environment is the concept incorporates how the nurses are

affected by the direct environment, but also how the nurses affect the working environment him or her. The concept of physical work environment is an interaction between the work organization and the individual. The component of physical environment in the hospital setting may seem more specific in the nursing profession than in other health care professions.

In that sense, presenteeism could have either positive or negative consequences on workers and organizations. As an example, nurses with mental health problems who are exposed to positive psychosocial work environments could fine the routine provided by work and a supportive climate to be helpful even though their productivity is impaired while on the job with mental illness.

Besides that, social status on presenteeism revealed that their relationship are complex when the nurses whose attend work, it may depend upon the discipline of nurses, their social status within an organization, their level of job, financial security, and also the care demands at work. Social status is defined as the relative respect, competence, and deference accorded to people, groups, and organizations in a society (Anderson, C., Hildreth, J., \& Howland, L., 2015). At its core, social status is about whom members of a society consider to hold more social value (Sedikides C. \& Guinote A., 2018). Social status can be achieved through education, occupation, and marital status. Their place within the stratification structure is determined by society's bar, which often judges them on success on financial, academic, and political. In Malaysia, nurses can be achieved through education to develop professionally and personally to ultimately achieve the respect and recognition which often judges them by their deserved. The table below stated that the details information total amount of nurses, dental nurses and community nurses until 31 December 2016 in Malaysia (Health Facts, 2017).

Table 1. Suvey Population at Health Human Resources, as of 31 December 2016

\begin{tabular}{clllll}
\hline & MoH & $\begin{array}{l}\text { Non } \\
\text { MoH }\end{array}$ & Private & Total & $\begin{array}{l}\text { Profess } \\
\text { ion: } \\
\text { Popula } \\
\text { tion }\end{array}$ \\
\hline Nurses & 65,227 & 6,798 & 30,539 & 102,564 & $1: 309$ \\
Dental & 2,785 & 60 & - & 2,845 & - \\
Nurses & & & & & \\
\hline
\end{tabular}

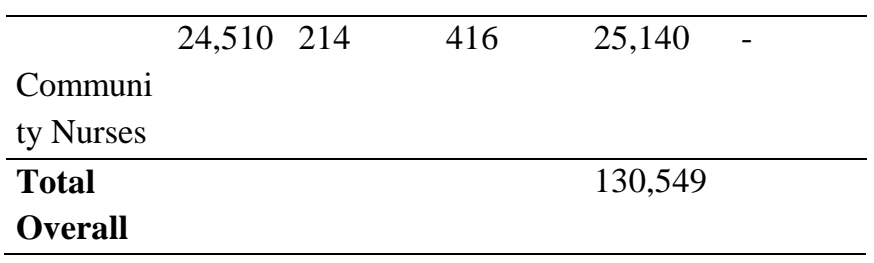

Source: MOH. (2017). Health Facts 2017. Malaysia: Ministry of health.

\section{LITERATURE REVIEW}

\section{A. Presenteeism}

According to Investopedia (2018), presenteeism is defined as the problem of employees who are not fully functioning in the workplace because of an illness, injury or other condition. Presenteeism is fairly common in most workplaces especially hospital which nurses who still show up to work even though they may be feeling ill, injured or going through some stressful situation. Even though the nurses may be physically at work, they may not be able to fully perform their duties and are more likely to make mistakes on the job. A patient who attend and receive the treatment and care at the hospital can be affected. So, the safety of the patients in term of treatment provided by nurse staffs should be ensured.

Furthermore, if the nurses are attending work while ill, it might exacerbate existing medical conditions, damage the quality of working life, and lead to impressions of ineffectiveness at work due to reduced productivity. From the view of the employee, presenteeism was important in that it might exacerbate existing medical conditions and damage the quality of work.

While the nurses may think that they are doing good by still showing up for work despite being injured, stressed or ill but they will make less productive or, even worse, make many mistakes while on the job, all of which can cost the company so much more than if they were to stay home. Furthermore, in the case of a physically sick employee who shows up to work, the cost of that employee's illness is likely to spread to other workers. In addition, the organization becomes more aware towards the importance of psychosocial factors among nurses which in give effect on nurses' presenteeism. The most important is the patients' satisfaction will be achieved once the nurses maintain their productivity on the job.

\section{B. Nature of Work}

Nature of nursing work is the type of work that he or she does. This can refer to the basic daily tasks carried out as part of a nurses' job and can refer to other non-routine tasks that may be required. Added together, the characteristics of these tasks comprise the nature of an nurses' work. The nature of this work may be summed up in the nurses' title (Lewis J., 2013). According to Noraini Othman \& Aizzat Mohd Nasurdin (2011), the nature of workplace adversity for nurses needs them to build the inner strengths in the form of psychological capital, in order to be able to cope with. Otherwise, it need to protect themselves from the effects of workplace adversity. 
Nurses may experience negative feelings such as burnout and depression without these inner strengths.

Nursing profession is usually connected with stressful stimuli such as unstable work time, excessive workload, and paper work and so on. Thus, nurses should provide quality of care while avoiding stress. They need to exhibit more efforts to face the demand of that profession. Physicall symptoms of work-related stress are common. According to Rakshit and Sharma (2016), they have made great efforts studying the negative effects of this stress on mental and physical health of employees for better understanding of its nature way to recognizing thus, to improve the mental health and the consequent increase in job efficiency.

Thus, time management can help nursing staff make stability between their occupational and individual lives more efficiency and effectively. It is important to manage their time to minimize stress for improving the quality of care and to reduce physical complaints. Regulation, control and domination maintenance of time can help in the prevention of wasting, resulting in maintaining manpower and preventing turnover, increasing job satisfaction and decreasing stress symptoms among nurses (Nasri et al., 2013).

\section{Social Status}

According to National Cancer Institute Dictionary of Cancer Terms (2018), the term social support is defined as a support is need to give such as psychological, physical and financial help from a network of family, friends, neighbours and community.

Yasmeen, Khan, Jamshaid, Salman and Abbas (2015) stated that there are strong correlations among four types of social support exists and behavioural coping has the strongest impact on the subjective well-being such as emotional social support, informational social support, material social support and instrumental social support.

Emotional social support refers to the confronting gestures like encouragement which are intended to alleviate, hopelessness, depressions, and current difficulties. Available resources and family helps the sufferers to enhance emotional strengths through motivation and encouragement, sharing of ideas and experiences to divert attention from illness and engage in healthy practices so that nurses feel better and important about themselves.

Informational support refers to giving advices, guidance and suggestions by the family members or teamwork to the nurses or useful information through press, mass media, and literature. It enables the nurses how to handle the situation on going to work when being ill. Teamwork become an additional pressure that expressed by employees as a result of qualitative research. Teamwork is a factor in which give a greater effect on sickness absence for the occupation group of healthcare provider.

Material support refers to the services to the nurses such as transportation, financial assistance for treatment and fulfilment of other needs. Instrumental support refers to the provision of financial assistance, material goods, or services. Also called tangible support, this form of social support encompasses the concrete, direct ways people assist others.

Other than that, House (1981) describes social support as "a flow of emotional concern, instrumental aid, information, and/or appraisal between people" (House, 1981, p. 26). Appraisal support is information relevant to self-evaluation i.e. providing feedback, affirmation, and social comparison. Emotional support, is providing empathy, trust, concern and listening. Informational support is providing advice, suggestion, directives and information. Instrumental support is directly helping a person in need such as, providing aid in kind, money, and time.

Social support increases one's feeling of being embedded in a network of communication and mutual obligation (Frese, 1999). Research has shown that nurses with supportive supervisors and colleagues were more satisfied with their work and inclined to stay in their job (Gauci, Borda, \& Norman, 1997; van der Heijden et al., 2009). Thus, the relationship between social supports on presenteeism revealed that support from the supervisory support affect the nurses' staff to monitor better on their patient when supervisor and other nurses became team player and help each other when have problems.

According to Luo $\mathrm{Lu}$ et al, positive personal and work-related factors such as hardy personality and work support which might perform protective roles in the presenteeism process have been overlooked (Luo Lu et al, 2013). Thus, their second aim of the study is to examine the role of supervisory support, an important work resource, as a stress buffer for people working in different cultural contexts.

The aim of the present study was two-fold which are to examine the impact presenteeism had on employees' work well-being across the Eastern and Western work contexts and to incorporate supervisory support as a stress buffer in the presenteeism process. For both the Chinese and British employees, they found a positive association between presenteeism and exhaustion.

They also found that supervisory support attenuated the relationship between presenteeism and exhaustion. In addition, they discovered that the Chinese employees committed more frequent act of sickness presenteeism and suffered greater strains than their British counterparts. The following discussion will be organised around two themes, contrasting the darker side of presenteeism with potential protectors against its impact in today's working world.

\section{Physical Work Environment}

According to Business Dictionary (2018), physical work environment is defined as when pertaining to a place of employment, the work environment involves the physical geographical location as well as the immediate surroundings of the workplace, such as an office building. Typically, other factors relating to the place of employment, such as the quality of the air, noise level, and additional perks. Other than that, other benefits of employment such as free child care or unlimited coffee or adequate parking. 


\section{Analysis of Presenteeism among Nurses}

Meanwhile, the physical work environment is the concept incorporates how the nurses are affected by the direct environment, but also how the nurses affect the working environment him or her. The concept of physical work environment is an interaction between the work organization and the individual. The component of physical environment in the hospital setting may seem more specific in the nursing profession than in other health care professions.

These include working environments where nurses lack autonomy and discretion, and where access to support and learning is limited when high levels of emotional exhaustion and burnout occur and also nurses experience frequent workplace stress. According to Jasper S et al (2012), these working environments where nurses lack autonomy and discretion to access their support and learning limited when high workloads and low reward. These also include working environments where nurses experience rotational shift patterns result in poor sleep patterns (Lin P-C et al, 2012). Mental health repercussions may occur where nurses are subjected to high public and professional expectations, workplace violence and role conflict in environments where there is high patient mortality, traumatic events or situations and conflict with physicians.

According to Letvak SA et al (2013), they have been strongly associated with nursing productivity, absenteeism and presenteeism (attending work while sick) with poor work performance, reduced productivity and workplace errors. They also have been strongly associated with decreased quality of patient care and low levels of patient satisfaction (Gartner FR et al, 2013). Indeed, in a prospective study in 10 call centres, adverse psychosocial work environments were associated with worse mental health and lower productivity from presenteeism. Presenteeism at baseline increased the risk for subsequent mental health problems, but there was some evidence that this association was only significant in the presence of an adverse work environment.

In that sense, presenteeism could have either positive or negative consequences on workers and organizations. As an example, nurses with mental health problems who are exposed to a positive psychosocial work environment could fine the routine provided by work and a supportive climate to be helpful even though their productivity is impaired while on the job with mental illness.

\section{E. Social Status}

Social status is defined as the relative respect, competence, and deference accorded to people, groups, and organizations in a society (Anderson et al, 2015). At its core, status is about whom members of a society consider to hold more social value (Sedikides C. \& Guinote A., 2018). According to Simandan D. (2018), these beliefs about who is more or less valued such as honorable, respectable and smart are broadly shared among members of a society. According to Anderson et al (2015), social status hierarchies appear to be universal across human societies with affording valued benefits to those who occupy the higher rungs such as nurses must have a better health, social approval, resources, influence, and freedom.

In modern societies, occupation is usually thought of as the main determinant of status, but other memberships or affiliations, such as ethnic group, religion, gender, voluntary associations, fandom and hobby can have an influence. Achieved status is when people are placed in the stratification structure based on their individual merits or achievements such as nurses could be achieved them through education, occupation, and marital status. Their place within the stratification structure is determined by society's bar, which often judges them on success on financial, academic, and political. In Malaysia, nurses can be achieved through education to develop professionally and personally to ultimately achieve the respect and recognition which often judges them by their deserved.

The German sociologist Max Weber developed a theory proposing that stratification is based on three factors that have become known as "the three P's of stratification": property, prestige and power. He claimed that social stratification is a result of the interaction of wealth, prestige status and power (Tony Waters et al, 2015).

Max Weber developed various ways that societies are organized in hierarchical systems of power such as the ways of social status, class power and political power. Class power is defined as an unequal access to resources. Social status or social power is defined as a social superior, that person will have power over you because you believe that person has a higher status than you do. As an example, head of nurses in the hospital have an authority to conduct activities on nurses because they have a higher status than nurses. Political power or political power can influence the hierarchical system of power because those that can influence what laws are passed and how they are applied can exercise power over others.

There is a relationship between social status and presenteeism are complex as it may depend upon the discipline of nurses, their social status within an organization, their level of job, financial security, and also the care demands at work This was opposed to staff physicians who were more concerned about the delivery of patient care if they were to call in sick. A similar finding is seen within nursing. In a qualitative study of Australian nurses, a sense of tension arose for nurses when determining whether to come to work while ill. This tension was created by previous interactions with supervisors who questioned the legitimacy of prior illnesses and focused on the need to report illnesses in a time frame that would ensure the adequacy of replacement staffing.

According to Blake KD et al (2013), there also may be significant financial incentives for going to work while ill for those lower in an organization's hierarchy due to a lack of paid sick leave or high levels of job insecurity. Unfortunaely, it will bring the rates of presenteeism can be influenced by care demands at work. In Nordic, the elder care staffs have the higher levels of work related demands due to understaffing and increased time pressures were they are associated with relatively large increases in presenteeism. 


\section{F. Conceptual Framework}

- Nature of work

- Social support

- Physical

work environment

Fig 1. Conceptual Framework of the Relationship between Nature Of Work, Social Support, Physical Work

Environment, Social Status And Presenteeism among Nurses

A conceptual framework developed for this study was adapted from Upton J. (2013) for the independent variables such as nature of work, social support, physical work environment and social status while for dependent variables, it was adapted from Koopman et al. (2002). The purpose of this conceptual framework was to help researcher to construct a good reliability with a high degree of validity questionnaire which help the researcher to measure what it was supposed to be measured in this study.

\section{METHODOLOGY/MATERIALS}

Research design is a type of analysis within qualitative, quantitative and mixed methods approaches that provide the specific direction for the procedures in a research design

(Creswell, 2014). Normally, researchers would use quantitative approach for a research that involves numerical data (Williams, 2007). The quantitative method is concern with numerical data. The data collected were analysing according to the pre-determined variables and measurement to attain the research objectives. For this research, quantitative approach is implementing in order to collect and analyse the data to reach the research objective.

\section{A. Research Procedure}

Research process is the procedure of collect, analyse and interpret to understand a research phenomenon (Leedy \& Ormrod, 2015). Researcher process able to help the researchers by provide the details and the skills essential to obtain the information required to complete an effective research. Every researcher must fulfil a series of steps in the research process, regardless of the topics that are study to help the researcher have better understand the steps involved in conduct a research. In this research, there are 8 steps involved in order to complete the study which are preliminary ideas, identify and formulate the research problem, review the literature, develop the hypothesis, objectives and research question, research design, define the population, collect data $\&$ analyse the data.

\section{B. Sampling Technique}

Sampling is a process where researcher estimates something about the whole population from some part of a population which is selected to observe (Thompson, 2012). One of the most popular probabilities sampling that commonly used by the researcher is the Simple Random Sampling. Random sampling is a method of selecting the

units from the population where all possible samples are equally likely to get selected (Singh \& Mangat, 2013). This indicates that everyone in the target population has an equal chance of being selected. This sample random sampling was used to collect the respondents among nurses from Perlis and Kedah state to achieve the research objective. All the population in the Perlis and Kedah state has the equal chance to be selected as the sample in the study for data collection.

\section{Sampling Size}

In order to determine sample size, a minimum number of questionnaires should be distributed in which not less than 30 and not more than 500 (Salkind, 2012). A total amount of nurses, dental nurses and community nurses until 31 December 2016 are 130,549 (Health Facts, 2017). Thus, the researcher distributed questionnaires to 120 nurses only to represent a cross-section of the population at Perlis state and Kedah state.

\section{Population}

The target population for a survey was the entire set of units for which the survey data are to be used to make inferences. Thus, the target population defines those units for which the findings of the survey are meant to generalize. The researcher had decided to select the nurses of Perlis state and Kedah state as the population in the study. Based on the information given by Health Human Resources until 31 December 2016, there were 130,549 employed as registered nurses, dental nurses and community nurses (Health Facts, 2017).

\section{E. Instruments}

The instrument was used in this study was adapted from Peterson Jessica Zara (2009) on her Phd. thesis about Job Stress, Job Satisfaction and Intention to Leave. The questionnaire consisted of three sections: Section A, Section $\mathrm{B}$ and Section C. Section A was focused on the dimensions of nature of work, social support, physical work environment and social status on presenteeism. Likert's Scale was used to measure the respondents' level of agreement from 1, strongly disagree to 5, strongly agree. Section B was focus on measuring presenteeism and this section also employed Likert scale measurement with 1 , never to 5, very often. Meanwhile, Section C was asked about demographic background of respondents such as age, gender, long employed as a registered nurse, highest education, working tome, shift work, frequency of presenteeism and self-rated health.

\section{F. Data Collection}

Through this research, total 120 questionnaires have been distributed to the nurses in state of Perlis and Kedah, and primary data is collected. Questionnaire had designed with 5 rating-scale question, which Likert's Scale was used to measure the respondents' level of agreement from 1, strongly disagree to 5, strongly agree and then distributed to those nurses which are involving. 


\section{Analysis of Presenteeism among Nurses}

The questionnaire is distributed to those nurses are in Perlis state and Kedah state. After the period of two weeks, the entire questionnaire that had been distributed is collected.

\section{G. Data Analysis}

The data that was gathered through the questionnaires were analysed using Statistical Package for Social Science (SPSS). In this study, researcher was used correlation analysis to understand the relationship between the elements of nature of work, social support, physical work environment and social status on presenteeism among nurses. The data has been collected from the questionnaire will analysed in the form of descriptive analysis. Descriptive statistics is a method of presenting the results of research conducted in the form of a simple statistical popular which are mean, standard deviation, Pearson and correlation. Other than that, Cronbach's Alpha, rules of thumb, validity and reliability is going to be tested in the research project.

\section{RESULTS AND FINDINGS}

\section{A. Demographic Background of Respondents}

Questions of demographic background of respondents were designed to gather respondents' demographic information which age, gender, long employed as a registered nurse, highest education, working tome, shift work, frequency of presenteeism and self-rated health. The table below summarised the analysis of demographic background of the respondents.

Table 2. Demographic Background

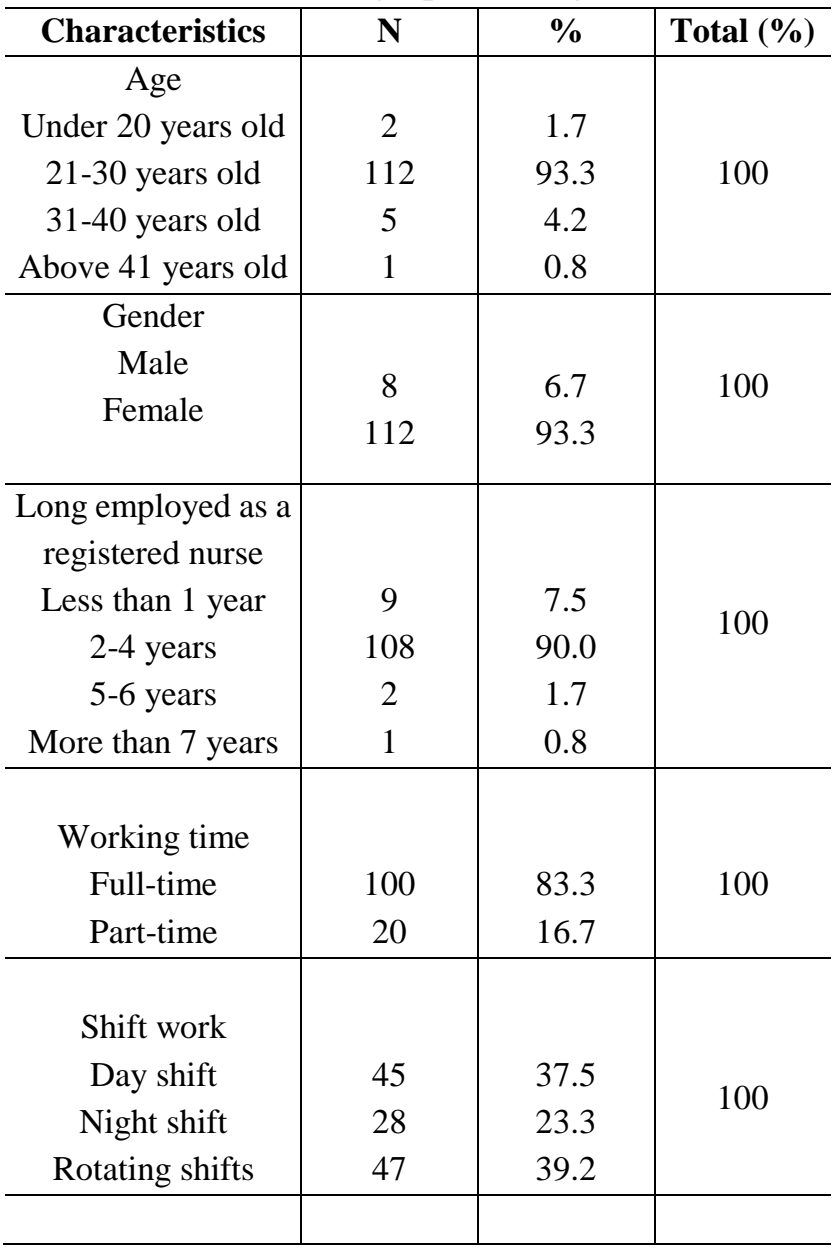

\begin{tabular}{c|c|c|c}
\hline $\begin{array}{c}\text { Frequency of } \\
\text { presenteeism }\end{array}$ & & & 100 \\
Never & 31 & 25.8 & \\
1 time & 76 & 63.3 & \\
2-5 times & 13 & 10.8 & \\
\hline & & & \\
Self-rated Health & & & \\
Excellent & 5 & 4.2 & \\
Very good & 45 & 37.5 & 100 \\
Good & 577 & 47.5 & \\
Fair & 13 & 10.8 & \\
\hline
\end{tabular}

The table above shows socio-demographic characteristics of the respondents. From the findings, the age was divided into 4 groups. The respondents within the range of 21 to 30 years old were the largest number among other groups of age which represent the percentage of $93.3 \%$ from the total respondents. Meanwhile, groups of respondents who aged from under 20 years and above 41 years old were the least respondents which occupied $1.7 \%$ and $0.8 \%$ respectively. The rest of the respondents aged between 31-40 years old represent $4.2 \%$ from the total respondents.

Besides, the finding shows that the majority of the respondents were female which occupied $93.3 \%$ from the total respondents. On the other hand, the minority of the respondents were male which represented $6.7 \%$ of the total respondents.

Based on the findings, the long employed as a registered nurse was divided into 4 groups. The respondents within the range of 2 to 4 years long employed were the highest number among the other groups which represent the percentage $90.0 \%$ from the total respondents. Meanwhile, groups of respondents who 5 to 6 years and more than 7 years long employed were the least respondents which occupied $1.7 \%$ and $0.8 \%$ respectively. The rest of the respondents who less than 1 year of long employed as a registered nurse represent $7.5 \%$ from the total respondents.

The findings on the table above shows that most of the respondents who participated in this study hold Diploma as their highest educational level $(58.3 \%)$ followed by Bachelor's Degree holders which represented $40.8 \%$. Meanwhile, $0.8 \%$ of the respondents hold Master's Degree.

In addition, the finding shows that the majority of the respondents were full-time working hours which occupied $83.3 \%$ from the total respondents. The rest of the respondents who participated in this study were part-time working hours represent $16.7 \%$ from the total respondents.

From the findings, the shifting hours were divided by 3 groups. The majority of the respondents were rotating shift hours which occupied $39.2 \%$ from the total respondents, followed by day shifting hours of the respondents which represented $37.5 \%$ from the total respondents. The rest of the respondents which they were working at night shifting hours represented $23.3 \%$ of the total respondents.

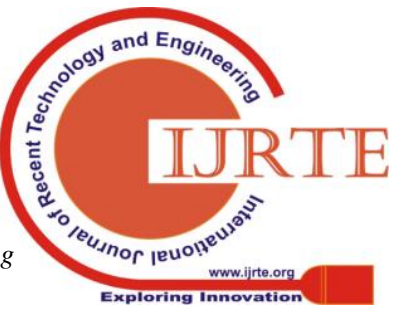


Based on the findings, the highest respondents who participated in this study took 1 time frequency of presenteeism $(63.3 \%[n=76])$ followed by the respondents that never took frequency of presenteeism $(25.8 \%[n=31])$. There were also 13 respondents took 2 to 5 times frequency of presenteeism which represented $10.8 \%$ of the total respondents.

Among the total number of 120 respondents, 57 respondents which representing $47.5 \%$ of the total respondents had good self-rated health while $37.5 \%$ which equals to 45 respondents had very good self-rated health. The rest only 13 respondents which representing $10.8 \%$ of the total respondents had fair self-rated health, followed by $4.2 \%$ which equals to 5 respondents had excellent self-rated health.

\section{B. Mean Analysis}

Table 3. Mean Analysis for all Independent Variables and Dependent Variable

\begin{tabular}{lll}
\hline Variables & Mean & SD \\
\hline Independent Variables & & \\
Nature of Work (NW) & 3.78 & .512 \\
Social Support (SS) & 4.07 & .626 \\
Physical Work Environment & 3.24 & .748 \\
(PWE) & & \\
Social Status (SST) & 3.16 & .505 \\
$\begin{array}{l}\text { Dependent Variable } \\
\text { Presenteeism (PR) }\end{array}$ & 3.19 & .507 \\
\hline
\end{tabular}

Based on the above table, it was found that Social Support has the highest mean score among other independent variables $[\mathrm{M}=4.07, \mathrm{SD}=.626]$. Nurses were shown to satisfied with social support from supervisor and coworkers in their workplace that leads directly to their presenteeism. On the other hand, descriptive analysis revealed that the overall mean score of dependent variable was Presenteeism with mean of 3.19 and Std. Deviation of .507 . These results indicated that most respondents agreed that they satisfied with the statement of items provided compared to other statement listed in the questionnaire.

\section{Normality Test}

According to Nornadiah \& Yap (2011), normality of sample distributed can be easily visualized through graphical methods such as Q-Q plot, histogram, stem-and-leaf plot, box plot as well as using statistics of test normality such as Kolmogorov-Smirnov, Shapiro-Wilk, skewness and kurtosis. In this study, in order to test the normality distribution of the data, the researcher used Kolmogorov-Smirnov to measure the normality of the data used to conduct the study.
Table 4. Normality Analysis using Kolmogorov-Smirnov

\begin{tabular}{|c|c|c|c|c|c|c|}
\hline & \multicolumn{6}{|c|}{ One-Sample Kolmogorov-Smirnov Test } \\
\hline & & $\begin{array}{l}\text { Nature } \\
\text { of Work }\end{array}$ & $\begin{array}{c}\text { Social } \\
\text { Suppor } \\
\mathbf{t}\end{array}$ & $\begin{array}{c}\text { Physi } \\
\text { cal } \\
\text { Work } \\
\text { Envir } \\
\text { onme } \\
\text { nt }\end{array}$ & $\begin{array}{l}\text { Social } \\
\text { Status }\end{array}$ & $\begin{array}{c}\text { Prese } \\
\text { nteeis } \\
\text { m }\end{array}$ \\
\hline \multicolumn{2}{|l|}{$\mathrm{N}$} & 120 & 120 & 120 & 120 & 120 \\
\hline \multirow{2}{*}{$\begin{array}{c}\text { Normal } \\
\text { Parameters }^{\mathrm{a}} \\
, \mathrm{b}\end{array}$} & Mean & 3.78 & 4.07 & 3.24 & 3.16 & 3.19 \\
\hline & $\begin{array}{c}\text { Std. } \\
\text { Devia } \\
\text { tion }\end{array}$ & .512 & .626 & .748 & .505 & .507 \\
\hline \multirow{3}{*}{$\begin{array}{c}\text { Most } \\
\text { Extreme } \\
\text { Differences }\end{array}$} & $\begin{array}{c}\text { Absol } \\
\text { ute }\end{array}$ & .129 & .121 & .079 & .096 & .098 \\
\hline & $\begin{array}{l}\text { Positi } \\
\text { ve }\end{array}$ & .128 & .121 & .060 & .096 & .098 \\
\hline & $\begin{array}{l}\text { Negat } \\
\text { ive }\end{array}$ & -.129 & -.111 & -.079 & -.073 & -.075 \\
\hline \multicolumn{2}{|c|}{$\begin{array}{c}\text { Kolmogorov-Smirn } \\
\text { ov } Z\end{array}$} & 1.413 & 1.329 & .865 & 1.071 & 1.073 \\
\hline \multicolumn{2}{|c|}{$\begin{array}{l}\text { Asymp. Sig. } \\
\text { (2-tailed) }\end{array}$} & .037 & .058 & .444 & .198 & .200 \\
\hline \multicolumn{7}{|c|}{ a. Test distribution is Normal. } \\
\hline & & & & & & \\
\hline
\end{tabular}

The table above shows the tests of normality run on the Independent Variables and Dependent Variable of the study. The independent variables were Nature of Work, Social Support, Physical Work Environment and Social Status. Meanwhile, Presenteeism represented the dependent variable of this study. According to Pallant (2010), a non-significant (Sig.) result represents data was normal. Any value above .05 indicates normality. In an SPSS output, if the value in the significant column was above .05 then data can be considered as normally distributed. Based on the table above, the significant value of Nature of Work, Social Support, Physical Work Environment, Social Status and Presenteeism were $.037, .058, .444, .198$ and .200 respectively. The significant value of Nature of Work was .037 in which suggesting violation of the assumption of normality and this was quite common in larger samples as this study has more than 100 respondents $(n=120)$. Thus, it can be concluded that the data was normally distributed.

\section{Reliability Test}

According to Jacobs (1991), reliability test was computed to show the extent to which test scores are free from errors of measurement. Moreover, standard error of measurement was very important because it alerts researcher to the fact that test scores were not exact and it always contains some errors. In order to test for internal consistency, reliability test was run for all items in independent variables and dependent variable. The test result for reliability of independent as well as dependent variable of the study was shown on the table below: 


\section{Analysis of Presenteeism among Nurses}

Table 5. Reliability of Independent Variables and Dependent Variable

\begin{tabular}{ll}
\hline Variables & $\begin{array}{c}\text { Cronbach's } \\
\text { Alpha }\end{array}$ \\
\hline Independent Variables & .811 \\
Nature of Work (NW) & .921 \\
Social Support (SS) & .912 \\
Physical Work Environment (PWE) & .701 \\
Social Status (SST) & \\
Dependent Variable & .703 \\
Presenteeism (PR)
\end{tabular}

The table above shows reliability test conducted for variables that contributed to presenteeism for nurses. According to Gliem \& Gliem (2003), Cronbach's Alpha reliability coefficient normally ranges between 0 and 1.0 whereas 1.0 was the greater internal consistency of the items in the scale. The larger coefficient is better (Jacobs, 1991). Moreover, Nunnaly (1978) indicates that 0.7 to be an acceptable reliability coefficient as the higher the score, the more reliable the generated scale.

According to the table, the value of Cronbach's Alpha for both the Independent Variables and Dependent Variable lies between 0.7 to 0.9 . It's showed that the dimensions were satisfactorily consistent. The highest Cronbach's Alpha value was .921 for Social Support and the lowest value was .701 for Social Status.

\section{E. Correlational Analysis}

Correlational analysis was commonly used in summarizing medical and scientific research data. This type of analysis was often useful in order to determine if a relationship exists between two different variables. Besides, researcher can also identify the strength of the relationship based on the findings of the analysis. According to Taylor (1990), the coefficient of the correlation was referred as Pearson's product-moment $r$ or $r$ coefficient which provides a direction to the findings whether it was positive or negative.

The range values of the coefficient are from -1 to 0 to +1 and if the coefficient value was zero, it indicated that there was no relationship between the variables. Furthermore, in order to interpret the degree of correlation coefficient, "Eyeball Method" was used to square the value of the correlation coefficient (Salkind, 2012). Table below showed the "Eyeball Method" used in the interpreting of correlation coefficient:

Table 6."Eyeball Method"

\begin{tabular}{cc}
\hline Correlations Between & Are said to be \\
\hline .8 and 1.0 & Very strong \\
.6 and .8 & Strong \\
.4 and .6 & Moderate \\
.2 and .4 & Weak \\
.0 and .2 & Very weak
\end{tabular}

In order to answer the research questions, the researcher has developed five hypotheses, in which coefficient values were then interpreted using the "Eyeball Method" in order to identify the strength of the relationship between the variables.
The table above showed the correlation between Nature of Work, Social Support, Physical Work Environment and Social Status with Presenteeism.

Table 7. Correlational Analysis of Nature of Work, Social Support, Physical Work Environment and Social Status with Presenteeism

\begin{tabular}{|c|c|c|c|c|c|}
\hline & $\begin{array}{l}\text { Nature } \\
\text { of Work }\end{array}$ & $\begin{array}{l}\text { Social } \\
\text { Supp } \\
\text { ort }\end{array}$ & $\begin{array}{l}\text { Physica } \\
1 \text { Work } \\
\text { Environ } \\
\text { ment }\end{array}$ & $\begin{array}{l}\text { Social } \\
\text { Status }\end{array}$ & $\begin{array}{l}\text { Present } \\
\text { eeism }\end{array}$ \\
\hline $\begin{array}{l}\text { Nature of } \\
\text { Work }\end{array}$ & 1 & $.811^{* * *}$ & $.691^{* *}$ & $.405^{* *}$ & $.407^{* *}$ \\
\hline $\begin{array}{l}\text { Social } \\
\text { Support }\end{array}$ & & 1 & $.527^{* *}$ & $.617^{* *}$ & $.619^{* *}$ \\
\hline $\begin{array}{l}\text { Physical } \\
\text { Work }\end{array}$ & & & 1 & $.256^{* *}$ & $.258^{* *}$ \\
\hline Environment & & & & & \\
\hline Social Status & & & & 1 & $.256^{* *}$ \\
\hline Presenteeism & & & & & 1 \\
\hline
\end{tabular}

There were a few relevant hypotheses that have been developed based on the study about the nature of work, social support, physical work environment and social status with presenteeism.

H1: There were nature of work, social support, physical work environment and social status which does affect presenteeism among nurses.

According to the table above, there were nature of work, social support, physical work environment and social status that affect presenteeism among nurses. According to the Pearson's product moment $r$, the relationship between social support and presenteeism was positive and strong as the indicated $r$-value is .619 that higher value rather than the relationship between nature of work and physical work environment with presenteeism. Thus, social support was one of independent variable that affect presenteeism among nurses. The first hypothesis is answered.

$\mathrm{H} 2$ : There is a relationship between nature of work and presenteeism among nurses.

Table 8. Correlations between Nature of Work and Presenteeism

\begin{tabular}{llll}
\hline & & $\begin{array}{l}\text { Nature } \\
\text { work }\end{array}$ & $\begin{array}{l}\text { of Presenteeis } \\
\text { m }\end{array}$ \\
\hline \multirow{3}{*}{$\begin{array}{lll}\text { Nature } \\
\text { work }\end{array}$} & $\begin{array}{l}\text { Pearson } \\
\text { of Correlation }\end{array}$ & 1 & $.407^{* *}$ \\
& Sig. (2-tailed) & & \\
& $\mathrm{N}$ & 120 & .000 \\
& & & 120
\end{tabular}

Published By:
Blue Eyes Intelligence Engineering
\& Sciences Publication


**. Correlation is significant at the 0.01 level (2-tailed).

According to the table above, there was a relationship between nature of work and presenteeism because the $p$-value was lower than $0.05(p=.000)$. This relationship between these two variables was positive and moderate as the $r$-value is .407. Thus, the second hypothesis is accepted.

H3: There is a relationship between social support and presenteeism among nurses.

Table 9. Correlations between Social Support and Presenteeism

\begin{tabular}{llll}
\hline & & $\begin{array}{l}\text { Social } \\
\text { Support }\end{array}$ & $\begin{array}{l}\text { Presenteeis } \\
\mathbf{m}\end{array}$ \\
\hline \multirow{3}{*}{ Social } & Pearson & 1 & $.619^{* *}$ \\
Support & Correlation & & \\
& Sig. (2-tailed) & & .000 \\
& $\mathrm{~N}$ & 120 & 120 \\
\hline
\end{tabular}

**. Correlation is significant at the 0.01 level (2-tailed).

The table above proves that there was a relationship between social support and presenteeism because the $p$-value was lower than $0.05(p=.000)$. According to the Pearson's product moment $r$, the relationship between two variables was positive and strong as the indicated $r$-value is .619. Thus, the third hypothesis is accepted.

H4: There is a relationship between physical work environment and presenteeism among nurses.

Table 10. Correlations between Physical Work Environment and Presenteeism

\begin{tabular}{|c|c|c|c|c|}
\hline & & & $\begin{array}{l}\text { Physical } \\
\text { Work } \\
\text { Environm } \\
\text { ent }\end{array}$ & $\begin{array}{l}\text { Presentee } \\
\text { ism }\end{array}$ \\
\hline \multirow{4}{*}{$\begin{array}{l}\text { Physical } \\
\text { Environment }\end{array}$} & & Pearson & 1 & $.258^{* *}$ \\
\hline & Work & Correlation & & \\
\hline & & Sig. (2-tailed) & & .004 \\
\hline & & $\mathrm{N}$ & 120 & 120 \\
\hline
\end{tabular}

**. Correlation is significant at the 0.01 level (2-tailed).

The table above shows that there was a relationship between physical work environment and presenteeism because the $p$-value is lower than 0.05 ( $p=.004)$. This relationship between these two variables was positive and weak as the indicated $r$-value was .258. Thus, the forth hypothesis is accepted.

H5: There is a relationship between social status and presenteeism among nurses.

Table 11. Correlations between Physical Work Environment and Presenteeism

\begin{tabular}{llll}
\hline & & $\begin{array}{l}\text { Social } \\
\text { Status }\end{array}$ & $\begin{array}{l}\text { Presentee } \\
\text { ism }\end{array}$ \\
\hline \multirow{3}{*}{ Social Status } & Pearson & 1 & $.256^{* *}$ \\
& Correlation & & \\
& Sig. (2-tailed) & & .002 \\
& $\mathrm{~N}$ & 120 & 120
\end{tabular}

The table above shows that there was a relationship between social status and presenteeism because the $p$-value is lower than $0.05(p=.002)$. This relationship between these two variables was positive and weak as the indicated $r$-value was .256. Thus, the forth hypothesis is accepted.

\section{CONCLUSION}

This study was carried out to investigate the relationship between nature of work, social support, physical work environment and social status with presenteeism among nurses in government hospital at Perlis and Kedah state.

Presenteeism is defined as nurses are attending work while ill that it might exacerbate existing medical conditions, damage the quality of working life, and lead to impressions of ineffectiveness at work due to reduced productivity (Aronsson Gustafson and Dallner, 2010). The relationship between natures of work on presenteeism revealed that the nurses whose attend work with the type of work that he or she does. This can refer to the basic daily tasks carried out as part of a nurses' job and can refer to other non-routine tasks that may be required. Added together, the characteristics of these tasks comprise the nature of a nurses' work. Other than that, the relationship between physical environment on presenteeism revealed that those nurses who attend work in healthy condition tends to delivered excellent services if the physical environment at the workplace such a facilities, pleasant condition in good maintenance.

Relationship between social supports on presenteeism revealed that support from the teamwork affect the nurses' staff to monitor better on their patient when all the team became team player and help each other when have problems and it simplify the nurses. Besides that, social status on presenteeism revealed that their relationship are complex when the nurses whose attend work, it may depend upon the discipline of nurses, their social status within an organization, their level of job, financial security, and also the care demands at work.

In the current study, the findings show that majority of the respondents in government hospital at Perlis and Kedah state were agreed with the relationship between nature of work, social support, physical work environment and social status with their presenteeism in the workplace. Thus, researcher can conclude that there was a relationship between nature of work, social support, physical work environment and social status with presenteeism among nurses in government hospital at Perlis and Kedah state. In addition, the findings show that social support that affect presenteeism among nurses. Since nurses' presenteeism seems to be the most important element in government hospital at Perlis and Kedah state, it is beneficial for the hospital management to encourage their nurse to pretend good and excellent without poor health condition and increases the frequency of presenteeism with the elements of nature of work, social support, physical work environment and social status.$$
\text { Exploring Innovation }
$$ 


\section{Analysis of Presenteeism among Nurses}

Further study should also be extended in larger scope, such as increase the number of government and private hospital involved and a comparative study between presenteeism of nurses in order to gain a better view of the field.

In conclusion, there is a relationship between the overall the relationship between nature of work, social support, physical work environment and social status with presenteeism among nurses in government hospital at Perlis and Kedah state is significant to each other. In addition, the social support does affect presenteeism among nurses. Thus, the findings have positively answered all the research questions and hypotheses addressed by the researcher in the early stage of the study.

\section{REFERENCES}

1. Anderson, C., Hildreth, J., \& Howland, L. (2015). "Is the Desire for Status a Fundamental Human Motive? A Review of the Empirical Literature". Psychological 574-601. doi:10.1037/a0038781. PMID 25774679.

2. Aronsson, G., Gustafsson, K., \& Dallner,M (2010) Sick but yet at work. An empirical study of sickness presenteeism. Journal of Epidemiology \& Community Health, 54,502-509.

3. Blake, K. D., Blendon, R. J., \& Viswanath, K. (2013). Employment and compliance with pandemic influenza mitigation recommendations. Emerg Infect Dis. 16(2):212-8. [PMC free article] [PubMed].

4. Caricati, L., Sala, R. L., Marletta, G., Pelosi, G., Ampollini, M., Fabbri, A., Ricchi, A., Scardino, M., Artioli, G., \& Mancini, T. (2014). Special Issue: This issue: Work Climate, Communication and Culture - Workforce Issues and Staff Retention Issue editor: Kristiina Hyrkas, Volume22, Issue8, November 2014.

5. Creswell, J. W. (2014). Research design: Qualitative, quantitative, and mixed methods approach. (Forth ed.). Thousand Oaks: Sage Publications.

6. Definition of Nurses (2018). Retrieved from https://www.icn.ch/nursing-policy/nursing-definitions.

7. Definition of Physical Work Environment (2018). Retrieved from http://www.businessdictionary.com/definition/work-environment.ht $\mathrm{ml}$.

8. Definiton of Presenteeism. Retrieved from https://www.investopedia.com/terms/p/presenteeism.asp.

9. Definition of Social Support (2018), Retrieved from https://www.cancer.gov/publications/dictionaries/cancer-terms/def/so cial-support.

10. Frese, M. (1999). Social support as a moderator of the relationship between work stressors and psychological dysfunctioning: a longitudinal study with objective measures. Journal of Occupational health Psychology, 4, 179-192.

11. Gauci-Borda, R., \& Norman. I. (1997). Factors influencing turnover and absence of nurses: a research overview. International Journal of Nursing Studies, 3, 385-394.

12. Gärtner, F. R., Nieuwenhuijsen, K., Dijk, F. J. H., \& Sluiter, J. K. (2012). Impaired work functioning due to common mental disorders in nurses and allied health professionals: the Nurses Work Functioning Questionnaire. Int Arch Occup Environ Health. 2012;85(2):125-38.PubMedView ArticleGoogle Scholar.

13. Gliem, J.A. \& Gliem R.R. (2003). Calculating, Interpreting \& Reporting Cronbach's Alpha Reliability Coefficient for Likert-Type Scales. Presented at the Midwest Research-to-Practice Conference in Adult, Continuing, and Community Education, The Ohio State University, Columbus, $\mathrm{OH}$.

14. Health Facts 2016. (2017). Health Facts 2016. Ministry of Health Malaysia. Retrieved from www.moh.gov.my.

15. House, J. (1981). The Nature of Social Support: Work Stress and Social Support. Reading, MA: Addison-Wesley.

16. Jacobs, L. C. (1991). Test Reliability. Retrieved on June 12, 2016 from http://www.indiana.edu/ best/bweb3/test-relaibility/.

17. Jasper, S., Stephan, M., Al-Khalaf, H., Rennekampff, H-O, Vogt. P., \& Mirastschijski, U. (2012). Too little appreciation for great expenditure? Workload and resources in ICUs. Int Arch Occup Environ Health. 2012;85(7):753-61.PubMedView ArticleGoogle Scholar.
18. Koopman, C., Kenneth, R. P., James, M., \& Talor, B. (2002). Stanford Presenteeism Scale: Health Status and Employee Productivity in Journal of Occupational and Environmental Medicine 44(1):14-20 - February 2002 with 5,053 ReadsDOI: 10.1097/00043764-200201000-00004, Source: PubMed.

19. Leely, P. D., \& Ormrod, J. E. (2015). Practical Research: Planning and Design (Global Edition) (Eleventh ed.). Harlow: Pearson Education Limited.

20. Letvak, S. A., Ruhm, C. J., \& Gupta, S. N. (2012). Nurses' presenteeism and its effects on self-reported quality of care and costs. $\begin{array}{lll}\text { Am J Nurs. 2012;112(2):30-8 } & \text { J }\end{array}$ doi:10.1097/1001.NAJ.0000411176.0000415696.f0000411179.Pub MedView ArticleGoogle Scholar.

21. Lewis, J. (2013). Nature of Work vs. Level of Work. Article of Human Resources Jobs. Retrieved from www.smallbusiness.chron.com/nature-work-vs-levelwork-33710.htm 1 (Retrieved March 27, 2013)

22. Lin, P. C., Chen, C. H., Pan, S. M., Pan, C. H., Chen, C. J., Chen, Y. M., et al. (2012). Atypical work schedules are associated with poor sleep quality and mental health in Taiwan female nurses. Int Arch Occup Environ Health. 2012;85(8):877-84.PubMedView ArticleGoogle Scholar.

23. Lu, L., Cooper, C. L., \& Lin, H. Y. (2013). A cross-cultural examination of presenteeism and supervisory support, available at www.emeraldinsight.com/1362-0436.htm

24. Nasri, S., Pazargadi, M., Tafreshi, M. \& Nassiri, N. (2013). The Correlation of Head Nurses' Time Management with Nurses' Job Satisfaction in Medical \& Surgical Wards of Hospitals in Arak Medical Sciences University. Journal of Nursing and Midwifery, 22 (79), pp 1-7.

25. Nornadiah M. R. and Yap B. W. (2011): Power Comparison of Shapiro-Wilk, Kolmogorov-Smirnov, Lillieforsand AndersonDarling Tests. Journal of Statistical Modeling and Analytics. Vol. 2. No. 1, 21-33.2011. ISSN 978-967-363-157-5.

26. Goldratt, E. M. (1990b). What is

27. Othman, N., \& Nasurdin, A. M. (2011). Work Engagement of Malaysian Nurses: Exploring the Impact of Hope and Resilience. World Academy of Science, Engineering and Technology International. Journal of Economics and Management Engineering, Vol:5, No:12, 2011

28. Pallant, J. (2010). SPSS Survival Manual: Survival Edition. (4th Ed.) USA: McGraw Hill. Pg.63.

29. Petterson, J. Z. (2009). Job stress, job satisfaction and intention to leave among new nurses. A thesis submitted for the degree of Doctor of Philosophy Graduate Department of Nursing Science. University of Toronto.

30. Rakshit, M. \& Sharma, Y. (2016). Occupational Stress and its impact on Physical and Psychological Health of Employees in Private Educational Organizations: Management Strategies. International Journal of Advanced Research in Education \& Technology (Online). 3(3), pp 96-101.

31. Salkind, Neil J. (2012). Exploring Research (8th ed.). NJ: Pearson Prentice Hall.

32. Sedikides, C., \& Guinote, A. (2018). "How Status Shapes Social Cognition: Introduction to the Special Issue, "The Status of Status: Vistas from Social Cognition". Social Cognition. 36(1): 1-3. doi:10.1521/soco.2018.36.1.1.

33. Simandan, D., 2018. Rethinking the health consequences of social class and social mobility. Social Science \& Medicine. https://doi.org/10.1016/j.socscimed.2017.11.037.

34. Singh, R., \& Mangat, N. S. (2013). Elements of Survey Sampling. New York: Springer Science+Busniness Media Dordrecht.

35. Thompson, S. K. (2012). Sampling (3rd ed.). Hoboken: John Wiley \& Sons, Inc.

36. Tony, W., \& Dagmar, W. (2015). Weber's Rationalism and Modern Society. Palgrave Macmillan.

37. Upton J. (2013) Psychosocial Factors. In: Gellman M.D., Turner J.R. (eds) Encyclopedia of Behavioral Medicine. Springer, New York, NY

38. Van der Heijden, B.I.J.M., Van Dam K., \& Hasselhorn, H.M. (2009) Intention to leave nursing: the importance of interpersonal work context, work-home interference and job satisfaction beyond the effect of occupational commitment. Career Development International, 14, 1362-1436.

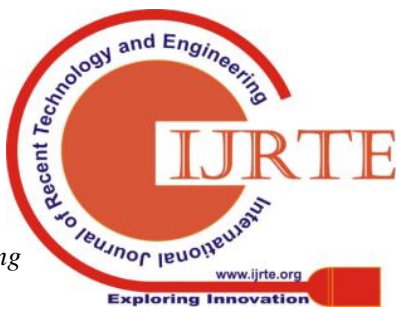


39. Waters, T. \& Dagmar, W. (2016). Are the terms "socio-economic status" and "social status" a warped form of reasoning for Max Weber?" Palgrave Communications 2, Article number: 16002 (2016) "Archived copy". Archived from the original on 2016-04-05. Retrieved 2016-04-24.

40. William, C. (2007). Research Methods. Journal of Business and Economic Research, 5, 65-72.

41. Workplace Health and Safety Queensland (2012). 'Work demands', Department of Justice and Attorney-General, Queensland.

42. Yasmeen, B., Khan, M. Z., Jamshaid, N., Salman, M., \& Abbas, S (2015). Heart and kidney patients; correlational patterns of social support with coping strategies and subjective well-being. Professional Medical Journal, 22(2), 235-243.

\section{Authors Profile}

Nur Syahirah Mohd Asri is associated with School of Business and Technopreneurship, Universiti Malaysia Perlis, her research interests include sociology, cultural and political sociology.

\section{Norshahrizan Nordin}

Ph.D (Operational Research), UMK, Malaysia

MSc. (Information \& Communication Technology), UUM, Malaysia

Bac. of Technology Management, UUM, Malaysia

Dip. In Manufacturing Technology, KUSZA, Malaysia

ResearchInterest:

Healthcare Management, Prioritization, Service Delivery, Nonlinear

Algorithm, Service Engineering, Kansei Engineering, Customer

Satisfaction and Dissatisfaction, Analytical Hierarchical Process (AHP),

Product Design, Manufacturing Technology, Technology Management,

Industrial Technology 